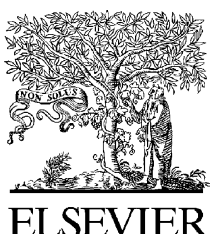

\title{
Achieving optimal asthma control: Can this be informed by recent studies of professional-patient communication?
}

The paper in this issue from Bellamy and Harris [1] is timely and of interest. A survey of patients and GPs from seven countries, it reports apparent inadequacies in current levels of asthma control, and a mismatch between GP and patient perceptions. The study itself has not used validated questions to assess asthma control but the questions used appear to be consistent with targets in current asthma guidelines-apart from the requirement to have no reliever usage in an eightweek period which is tighter than many current guidelines suggest. Notwithstanding that the high levels of asthma symptoms and lifestyle limitation certainly support ongoing reports of deficiencies in asthma control, GPs' views correspond to information within guidelines and evidence from recent studies with the majority believing that asthma control is achievable for a substantial proportion of asthma patients even though their patients are not achieving this objective. GPs were concerned that their patients accepted their symptoms as normal and were frustrated that patients were not more forthcoming about their symptoms.

Educating asthmatic patients to recognize accurately and to respond to their own symptoms is critical. Under-treatment of symptoms because of poor perception has been claimed to increase the risk of fatal asthma [2], as well as impacting on patient quality of life [3]. However, Bellamy and Harris's findings correspond with those from previous surveys: asthma control, as measured against internationally agreed guidelines [4], is often sub-optimal $[5,6]$. Why is this the case? The
Living and Breathing study [7] identified that the majority of patients with mild to moderate asthma were satisfied with the level of asthma care they received, despite a high level of daily symptoms and night-time symptoms. Respondents' satisfaction with asthma care fell by almost half once they were shown the asthma symptom management goals outlined in international guidelines. This finding supports the observation that asthma patients do not realise they could be better. Most respondents were unaware of these goals and, indeed, expressed scepticism about them because their own experience did not match these expectations.

Thus, sub-optimal asthma control is inherently related to lack of education, or knowledge $[8,9]$. This, in turn, underpins the mismatch between patient and professional perceptions of what level of control can be achieved. Education is the key to optimising control, opening up the consultation to discuss symptoms, and supporting patients in asthma management. Education helps to increase patients' knowledge about their health, condition and self-care, and has been associated with improvements in disease control [10].

However, what is the best method for delivering asthma information and self-management advice to patients? Bellamy and Harris conclude that patients should be more proactive in reporting symptoms, but acceptance of sub-optimal control has consequences for patient help-seeking behaviour. Jones et al.'s study of COPD patients indicated that when patients are unsure as to which symptoms indicate poor control or an exacerbation, they are 
reluctant to "bother the doctor" [11]. Similarly, asthma patients tend not to voice non-medical variables within the consultation, in the belief that these are not relevant [12]. Thus, opportunities within the consultation for the GP to work with the patient in order to optimise asthma management may be limited due to patients not recognizing symptoms, or patients assuming that information is not relevant and thus not presenting it in the consultation. Patients differ in terms of asthma characteristics, such as symptoms and triggers, as well as personal attributes and lifestyles [13]. The onus is on the healthcare professional to use patient-centred communication skills [14] in order to gather appropriate information from the patient on a range of disease and illness characteristics [15], and then to use this as the basis for providing education and information to the individual patient [16]. The process of providing education is critical. For example, a study of provision of smoking cessation advice in primary care [17] showed that patients wanted advice and education that was personalised, positive, pertinent and practical but did not wish to be "preached to".

We know that the behaviour of GPs in practice seems to be based on a desire to work in partnership with the patient $[18,19]$ thus avoiding risking damage to the doctor-patient relationship. GPs may not wish to explore patient symptoms and level of control in more depth, due to the possible misperception that patients are not willing to do so. However, patients may be more open to discussing their symptoms within the consultation when they are made aware of what can indeed be achieved in terms of asthma control, particularly when advice about achieving better control is personalised and tailored to their individual needs [20].

Encouraging patients to report symptoms, identify goals, and work with the healthcare professional, depends on the full involvement of patient, GP, and practice nurse in partnership [21]. Training healthcare professionals in patientcentred asthma management so that they develop the communication skills required to help a range of patients with individual disease characteristics, personal attributes and lifestyles, may be an important factor in asthma management. We suggest that preparing professionals to work with patients towards optimal asthma management has several components:

- Specify professional communication behaviours: studies are now beginning to identify the precise clinician behaviours [22] which impact favourably on patient outcomes $[23,24]$ but future work is required to investigate if this data is applicable to UK settings and healthcare providers.

- Encourage optimal asthma management by using communication behaviours that encourage greater involvement of patients in the consultation - this can be beneficial in terms of disease control and patient view of consultations (14).

- Improve clinicians' awareness of their patients' health beliefs [25] and of the behavioural processes involved in determining individuals' ability to regulate their own health behaviour [21]. The onus is on the healthcare professional to identify patient beliefs and views, in order to address any misconceptions (such as low expectations of the level of control which may be achievable through treatment) that may be based on lack of accurate information. In COPD we know that lack of understanding leads to delay in presenting an exacerbation, which, in turn, has a substantial impact on morbidity and mortality [26]. It may be that better understanding of one's asthma (a positive change in illness representations [25]) promotes intention to perform new, more effective selfcare behaviours [27].

In conclusion, the mismatch between patient and GP beliefs and goals identified by Bellamy and Harris is likely to be associated with patient education needs and sub-optimal communication within the consultation, particularly with regard to identifying patient beliefs and goals. If outcomes for patients receiving asthma treatment are to improve, healthcare professionals should raise patient expectations by taking into account what matters to patients in terms of symptom control, and then setting treatment goals accordingly.

\section{References}

[1] Bellamy D, Harris T. Poor perceptions and expectations of asthma control: Results of the International Control of Asthma Symptoms (ICAS) survey of patients and general practitioners. Primary Care Resp J 2005;14(4):2528.

[2] British Thoracic Association. Death from asthma in two regions of England. Brit Med J 1982;285:1251-15.

[3] Ehrs P, Larsson K. Treatment improves quality of life in patients with poor perception of asthma. Primary Care Resp J 2004;13:42-7.

[4] National Institutes of Health/National Heart, Lung and Blood Institute. Global Initiative for Asthma: Pocket guide for asthma management and prevention. A pocket guide for physicians and nurses. 2002; NIH Publication No. 02-3659.

[5] Rabe KF, Vermeire PA, Soriano JB, Maier WC. Clinical management of asthma in 1999: the Asthma Insights and Reality in Europe (AIRE) study. Eur Respir J 2000;16:802-7. 
[6] Price DB, Ryan D, Pearce L, Bride F. The AIR study: asthma in real life. Asthma Journal 1999;4:74-8.

[7] Haughney J, Barnes G, Partridge M, Cleland J. The Living \& Breathing Study: a study of patients' views of asthma and its treatment. Primary Care Resp J 2004;13:28-35.

[8] Powell H, Gibson PG. Options for self-management education for adults with asthma. The Cochrane Database of Systematic Reviews 2002, Issue 3. Art. No.: CD004107. doi:10.1002/14651858.CD004107.

[9] Gruffyd Jones K, Bell J, Fehrenbach C, Pearce L, Grimley D. Understanding patient perceptions of asthma: results of the asthma control and expectations (ACE) survey. Int J Clin Pract 2002;56:89-93.

[10] Weingarten SR, Henning JM, Badamgarav E, et al. Interventions used in disease management programmes for patients with chronic illness - which ones work? Metaanalysis of published reports. Brit Med J 2002;325:925.

[11] Jones RCM, Hyland ME, Hanney K, Erwin J. A qualitative study of compliance with medication and lifestyle modification in Chronic Obstructive Pulmonary Disease (COPD). Primary Care Resp J 2004;13:149-54.

[12] Moffat $M$. The management of severe and difficult asthma in primary care: a qualitative study. Unpublished PhD thesis, University of Aberdeen 2004.

[13] Lahdensuo A. Clinical Review - Guided self management of asthma - how to do it. Brit Med J 1999;319:759-60.

[14] Maguire P, Pitceathley C. Key communication skills and how to acquire them. Brit Med J 2002;325:697-700.

[15] Lewin SA, Skea ZC, Entwhistle V, Zwarenstein M, Dick J. Interventions for providers to promote a patient-centred approach in clinical consultations. The Cochrane Database of Systematic Reviews 2001, Issue 4. Art. No.: CD003267. doi:10.1002/14651858.CD003267.

[16] Makoul G, Arntson P, Schofield T. Health promotion in primary care: physician-patient communication and decision making about prescription medications. Social Science and Medicine 1995;41:1241-54.

[17] Cleland JA, Thomas M, Pinnock H. The views and attitudes of general practitioners and smokers towards provision of smoking cessation advice; a qualitative study. Primary Care Resp J 2004;13:144-8.

[18] Coleman T, Wynn A, Stevenson K, Cheater F. Qualitative study of pilot payment aimed at increasing general practitioners' antismoking advice to smokers. Brit Med J 2001;323:432-54.
[19] Coleman T, Murphy E, Cheater F. Factors influencing discussion of smoking between general practitioners and patients who smoke: a qualitative study. $\mathrm{Br} \mathrm{J}$ Gen Pract 2000;50(452):207-10.

[20] Butler CC, Pill R, Stott NC. Qualitative study of patients' perceptions of doctors' advice to quit smoking: implications for opportunistic health promotion. BMJ (Clinical research ed) $1998 ; 316(7148): 1878-81$.

[21] Clark NM, Gong M. Management of chronic disease by practitioners and patients: are we teaching the wrong things. Brit Med J 2000;320:572-5.

[22] Michie S, Johnston M. Changing clinical behaviour by making guidelines specific. Brit Med J 2004;328:343-5.

[23] Clark NM, Gong M, Schork A, et al. Impact of education for physicians on patient outcomes. Pediatrics 1998;101:831-6.

[24] Clark NM, Gong M, Schork A, et al. Long term effects of asthma education for physicians on patient satisfaction and use of health services. Eur Respir J 2000;16:15-21.

[25] Leventhal $H$, Diefenbach $M$, Leventhal EA. Illness cognitions: using common sense to understand treatment adherence and affect cognition interactions. Cognitive Ther Res 1992;16:143-63.

[26] Scharloo M, Kaptein AA, Weinman J, et al. Illness perceptions, coping and functioning in patients with rheumatoid arthritis, chronic obstructive pulmonary disease and psoriasis. J Psychosom Res 1998;44:573-85.

[27] Madison JM, Irwin RS. Chronic obstructive pulmonary disease. Lancet 1998;352:467-73.

Jennifer Cleland*
David Price
Department of General Practice and
Primary Care, University of Aberdeen
Foresterhill Health Centre, Westburn Road
Aberdeen, AB25 2AY, UK
*Corresponding author. Tel.: +441224553969
fax: +441224550683
E-mail address: jen.cleland@abdn.ac.uk
(J. Cleland)
16 May 2005

16 May 2005

Available online at www.sciencedirect.com

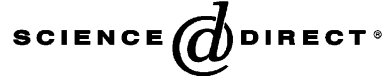

